\title{
The Alaska Arctic Vegetation Archive (AVA-AK)
}

\author{
Donald A. Walker*, Amy L. Breen, Lisa A. Druckenmiller, Lisa W. Wirth, Will Fisher, Martha K. Raynolds, \\ Jozef Šibík, Marilyn D. Walker, Stephan Hennekens, Keith Boggs, Tina Boucher, Marcel Buchhorn, \\ Helga Bültmann, David J. Cooper, Fred J.A Daniëls, Scott J. Davidson, James J. Ebersole, Sara C. Elmendorf, \\ Howard E. Epstein, William A. Gould, Robert D. Hollister, Colleen M. Iversen, M.Torre Jorgenson, Anja Kade, \\ Michael T. Lee, William H. MacKenzie, Robert K. Peet, Jana L. Peirce, Udo Schickhoff, Victoria L. Sloan, \\ Stephen S. Talbot, Craig E. Tweedie, Sandra Villarreal, Patrick J. Webber, Donatella Zona
}

\begin{abstract}
The Alaska Arctic Vegetation Archive (AVA-AK, GIVD-ID: NA-US-014) is a free, publically available database archive of vegetation-plot data from the Arctic tundra region of northern Alaska. The archive currently contains 24 datasets with 3,026 non-overlapping plots. Of these, $74 \%$ have geolocation data with 25- $\mathrm{m}$ or better precision. Species cover data and header data are stored in a Turboveg database. A standardized Pan Arctic Species List provides a consistent nomenclature for vascular plants, bryophytes, and lichens in the archive. A web-based online Alaska Arctic Geoecological Atlas (AGA-AK) allows viewing and downloading the species data in a variety of formats, and provides access to a wide variety of ancillary data. We conducted a preliminary cluster analysis of the first 16 datasets (1,613 plots) to examine how the spectrum of derived clusters is related to the suite of datasets, habitat types, and environmental gradients. We present the contents of the archive, assess its strengths and weaknesses, and provide three supplementary files that include the data dictionary, a list of habitat types, an overview of the datasets, and details of the cluster analysis.
\end{abstract}

Keywords: Circumpolar, cluster analysis, database, tundra, Turboveg, vegetation classification

Nomenclature: Elven (2011) for vascular plants; Kristinsson et al. (2010) for lichens; Belland (2012, unpublished Arctic moss database for the Conservation of Arctic Flora and Fauna) for mosses; and Konstantinova \& Bakalin (2009) for liverworts.

Abbreviations: AVA = Arctic Vegetation Archive; AVA-AK = Alaska Arctic Vegetation Archive; GIVD = Global Index of Vegetation-Plot Databases.

Submitted: 28 March 2016; revised version submitted: 8 May 2016; accepted: 17 May 2016

Co-ordinating Editor: Jürgen Dengler

*Corresponding author's address: Alaska Geobotany Center, Intitute of Arctic Biology and Department of Biology and Wildlife, University of Alaska Fairbanks, Fairbanks, AK 99775, United States; dawalker@alaska.edu. Complete addresses of all authors can be found at the bottom of the paper. 


\section{GIVD Fact Sheet}

\section{GIVD Database ID: NA-US-014}

Alaska Arctic Vegetation Archive

Database manager(s): Amy Breen (albreen@alaska.edu); Lisa Druckenmiller (Iddruckenmiller@alaska.edu); Jozef Sibik (jozef.sibik@savba.sk) Owner: Donald A. Walker, Amy L. Breen, Jozef Sibik, Lisa Druckenmiller and Martha K. Raynolds

Scope: The Alaska Arctic Vegetation Archive (AVA-AK) is a regional database that is part of the larger Arctic Vegetation Archive. The database contains vegetation plots from homogeneous plant communities with tables of cover or cover-abundance scores for all species, and accompanying environmental site data. Data are collected using Braun-Blanquet, US National Vegetation Classification protocols, or comparable methods.

\section{Availability: free online}

Database format(s): TURBOVEG

Plot type(s): normal plots; time series

Non-overlapping plots: 3,026

Total no. of plot observations:

3,156

Countries: CA: $5.0 \%$; US: $95.0 \%$

Formations: Forest: $5 \%=$ Terrestrial: $5 \% / /$ Non Forest: Aquatic: $3 \%$ (Fresh water: $3 \%$ ), Semi Aquatic: 12\% ( Fresh water: 12\%) , Terrestrial: $80 \%$ ( Arctic alpine: $80 \%$ )

Guilds: all vascular plants: $100 \%$; bryophytes (terricolous or aquatic): $98 \%$; lichens (terricolous or aquatic): $96 \%$

Environmental data: altitude: $68 \%$; slope aspect: $84 \%$; slope inclination: $84 \%$; microrelief: $15 \%$; soil depth: $48 \%$; surface cover other than plants (open soil, litter, bare rock etc.): $40 \%$; soil pH: $64 \%$; other soil attributes: $73 \%$

Performance measure(s): cover: $100 \%$; measurements like diameter or height of trees: $1 \%$; biomass: $13 \%$

Geographic localisation: GPS coordinates (precision $25 \mathrm{~m}$ or less): $74 \%$; point coordinates less precise than GPS, up to $1 \mathrm{~km}$ : $7 \%$; political units or only on a coarser scale (>10 km): $19 \%$

Sampling periods: $1950-1959: 4.0 \%$; 1960-1969: 5.0\%; 1970-1979: 5.0\%; 1980-1989: 30.0\%; 1990-1999: 30.0\%; 2000-2009: 41.0\%; 20102019: $6.0 \%$

Information as of 2016-17-05; further details and future updates available from http://www.givd.info/ID/NA-US-014

\section{Introduction}

The goal of the Arctic Vegetation Archive (AVA) project is to gather all the available Arctic vegetation plot data into a publically accessible database and apply it to northern issues, including a circumpolar Arctic vegetation classification (Walker et al. 2013a, 2013b, Walker 2014a). The conceptual basis for the AVA originated in the Flora Group of the Conservation of Arctic Flora and Fauna (CAFF) (Walker \& Raynolds 2011). CAFF is the biodiversity working group of the Arctic Council, which is an intergovernmental forum that promotes international cooperation, coordination and interaction among the eight Arctic Nations. The plan for the AVA calls for each Arctic nation to build their piece of the panarctic archive. Here we describe the Alaska AVA (AVA-AK, GIVD-ID: NA-US-014), the first prototype for the AVA. A workshop to organize the Alaska piece was held in Boulder, CO, October, 2013, where most of the key datasets were presented in a series of papers (Walker 2014b). This Long Database Record describes the methods for constructing the AVA-AK, its current content, and the results of a preliminary numerical analysis.

\section{Background}

The geographic scope of the AVA-AK is mainly the Arctic portion of Alaska, although the archive also contains a few boreal plots and a dataset from Canoe and Trout lakes in far northwestern Canada (Fig. 1). Early vegetation reconnaissance surveys in Arctic Alaska were conducted during the exploration of Naval Petroleum Reserve No. 4 and early surveys of reindeer ranges in the 1950s. More focused vegetation surveys began with the International Biological Program (IBP) Tundra Biome research starting in the late 1960s. These and later surveys were aimed at an ecological understanding of the controls of tundra vegetation spatial and temporal patterns. $\mathrm{Nu}-$ merous vegetation surveys in the 1980s up to the present were done in conjunction with a wide variety of regional landcover mapping and process-level studies. A brief overview of the history and current contents of the AVAAK are in Supplement S1 with key references. A list of the current datasets in the AVA-AK is in Table S1-1, along with a summary of the available ancillary data and the current status of each record. 


\section{The AVA-AK Turboveg database}

The AVA-AK uses a Turboveg v2 database management system to store, select, and export the plot data (Hennekens \& Schaminée 2001). The archive includes standardized species-cover and header data. The workflow for the database includes data gathering, digitization of data, georeferencing of plots, assembly of bibliographic materials, import into Turboveg, and creation of metadata (Breen et al. 2014). Data are standardized for import into Turboveg according to a data dictionary (Supplement S2: Table S2-1). The header data include those required for all Turboveg datasets (plot coordinates, elevation, basic environmental data, and canopy structure information) and some recommended environmental data specific to the AVA-AK including habitat type (Supplement S2: Table S2-2).

The Pan-Arctic Species List (PASL, beta 1.1) (Raynolds et al. 2013) provides a uniform taxonomic framework for plant species names. The PASL is composed of the Pan Arctic Flora checklist for vascular plants (Elven 2011) and lists of accepted species names and synonyms for the Arctic lichens (Kristinsson et al. 2010), Arctic mosses (Belland unpubl., provided in 2012), and a Russian list of Arctic liverworts (Konstantinova \& Bakalin 2009).

Forty-seven datasets containing approximately 5,300 plots were initially identified for possible inclusion in the database (Breen et al. 2014). This initial list was based largely on our personal knowledge of the literature and other known vegetation datasets in northern Alaska, several of which are unpublished. Several other potential datasets were identified later. After closer evaluation, some of the datasets were excluded from the Turboveg database for various reasons, including: (1) poor quality of the taxonomic information; (2) use of sampling methods that did not result in complete species lists from homogenous areas of tundra; (3) species cover values were available only in summary form for vegetation types and did not include data from individual plots; and (4) the original data were unavailable because they were considered proprietary information. In some cases, datasets were included in the AVA-AK but with notes regarding the quality of the data that could limit future applications. For example, some datasets were of historic value but had no photographs of the plots or specific location

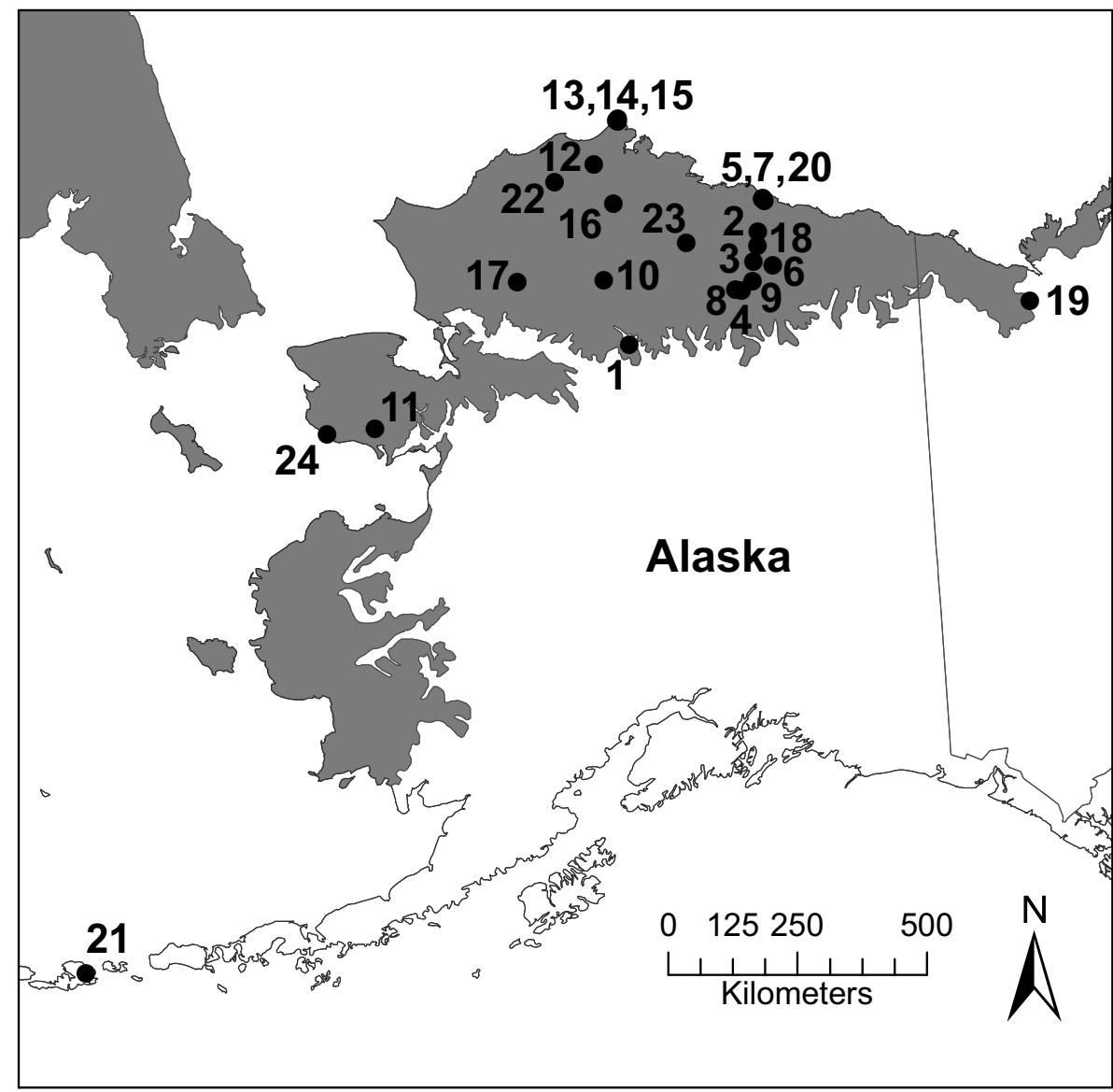

Fig. 1. Locations of the 24 datasets currently in the Turboveg AVA-AK database. The shaded area is the region of Arctic tundra. Names and authors of the datasets are in Supplement S1: Table S1-1. 
information. Some datasets had good information for vascular plants, but weak or no information for cryptogams. Datasets that were not included in the AVA-AK Turboveg database were still referenced and described in a "Catalog" record of the Alaska Arctic Geoecological Atlas (see below).

The AVA-AK Turboveg database currently contains 24 datasets (3,026 plots) (Fig. 1 and Supplement S2). Another 13 datasets, containing approximately 1,000 plots are in the process of review and data entry. The data are also being entered into the VegBank database (http://vegbank.org), which is the main vegetation-plot archive for the U.S. (Peet et al. 2012). Vegetation metadata standards follow those of the Global Index of Vegetation-Plot Databases (GIVD) (Dengler et al. 2011) and standards developed for the Oak Ridge National Laboratory Distributed Active Archive Center, which is the archive of the National Aeronautics and Space Administration's Arctic Boreal Vulnerability Experiment (http://above.nasa.gov), which funded the AVA-AK. The 3,024 AVA-AK plots are also included in sPlot, a global vegetation-plot database with standardised plant nomenclature and header data (Dengler \& the sPlot Core Team 2014).

\section{A web-based approach for viewing and accessing the plot data}

The Turboveg database is a free and publically-accessible through a web-based portal, the Alaska Arctic Geoecological Atlas (AGA-AK, http://alaskaaga.gina.alaska. edu) housed at the Geographic Information Network of Alaska (GINA), University of Alaska Fairbanks. Each dataset has a "Catalog" record, where a detailed description of the dataset can be found along with links to a variety of available data and information, including: (1) The main Turboveg file containing all the species data for all the datasets; (2) a link to the Turboveg software; (3) raw source data, which are stored in their original form as .csv files; and (4) available ancillary data. Ancillary data can include any of the following: original species and environmental data before they were standardized for the Turboveg database, key publications and data reports, maps of plot locations, plot photographs, vegetation structure information, soil and environmental site factors, aboveground phytomass, and ground-based spectral information (e.g. hand-held spectroscopy, Normalized Difference Vegetation Index (NDVI), and leaf-areaindex (LAI) measurements).

\section{Preliminary cluster analysis}

We performed a preliminary cluster analysis to characterize the contents of the AVA-AK up until June 2015. The purpose of the analysis was to determine if a numerical anlaysis would result in meaningful clusters that would prove useful for characterization of the contents of the archive and for vegetation classification and analysis. These datasets included 1,603 plots within 16 broad habitat types (Supplement S2: Table S2-1, Accession numbers 1 to 16$)$, representing 16 high quality datasets from most habitat types along two long north-south bioclimate transects from the Beaufort Sea to the Brooks Range on the eastern transect and from Barrow to the Seward Peninsula on the western transect. See Supplement S3 for details of the cluster analysis.

The peak separability of clusters in the diagram, using the crispness of classification method (Botta-Dukát et al. 2005) within the JUICE program (Tichý et al. 2011), was achieved with four clusters as shown by the top color bar in Fig. 2. At this level, the clusters are heterogeneous, but show sensible ecological organization. Cluster A is the largest and most heterogeneous cluster with 684 relevés, containing many azonal communities, including most wetlands, riparian shrublands, deep late-melting snowbeds, and pioneering communities along streams, rock crevices, and talus slopes. Cluster B contains 233 relevés, mostly moist to dry acidic ericaceous heath communities, including tussock tundra dominated by Eriophorum vaginatum. Cluster $C$ contains 269 relevés, the bulk of which are from the communities in the one large alpine dataset from the Arrigetch Peaks region in the Brooks Range with many dry-graminoid- and forb-dominated communities, and drier dwarf-shrub snowbeds dominated by Cassiope tetragona and lichens. Cluster D contains 382 relevés, most of which are from dry nonacidic tundra and tundra steppe communities on southfacing slopes of pingos and which contain high numbers of Beringian species. Pingos are large ice-cored domeshaped mounds, sometimes with heights exceeding 20 meters, which are important landscape components of the thaw-lake plains of northern Alaska (Walker 1990). There is a clear break at the highest level in the dendrogram between communities on mainly wet to moist acidic substrates of clusters $\mathrm{A}$ and $\mathrm{B}$ and the mainly moist to dry nonacidic substrates of clusters $\mathrm{C}$ and $\mathrm{D}$.

The next highest level of separation power was achieved with 17 subclusters that reflect geographical or ecological affiliation of groups of plant communities (Fig. 2, labels on the branches of the dendrogram). Table S3-1 in Supplement S3 contains lists of the diagnostic, constant and dominant taxa within each of the 17 subclusters that were used to further characterize the four main clusters. Several subclusters are nearly entirely composed of plots from one of two large datasets. Subclusters 11, 12, and 13 are almost entirely from the Arrigetch Peaks dataset (Cooper 1986), and subclusters 14, 15, and 16 are nearly totally from the Pingos dataset (Walker 1990).

The preliminary cluster analysis revealed that the higher hierarchical levels of the dendrogram generally correspond to higher rank units such as phytosociologi- 

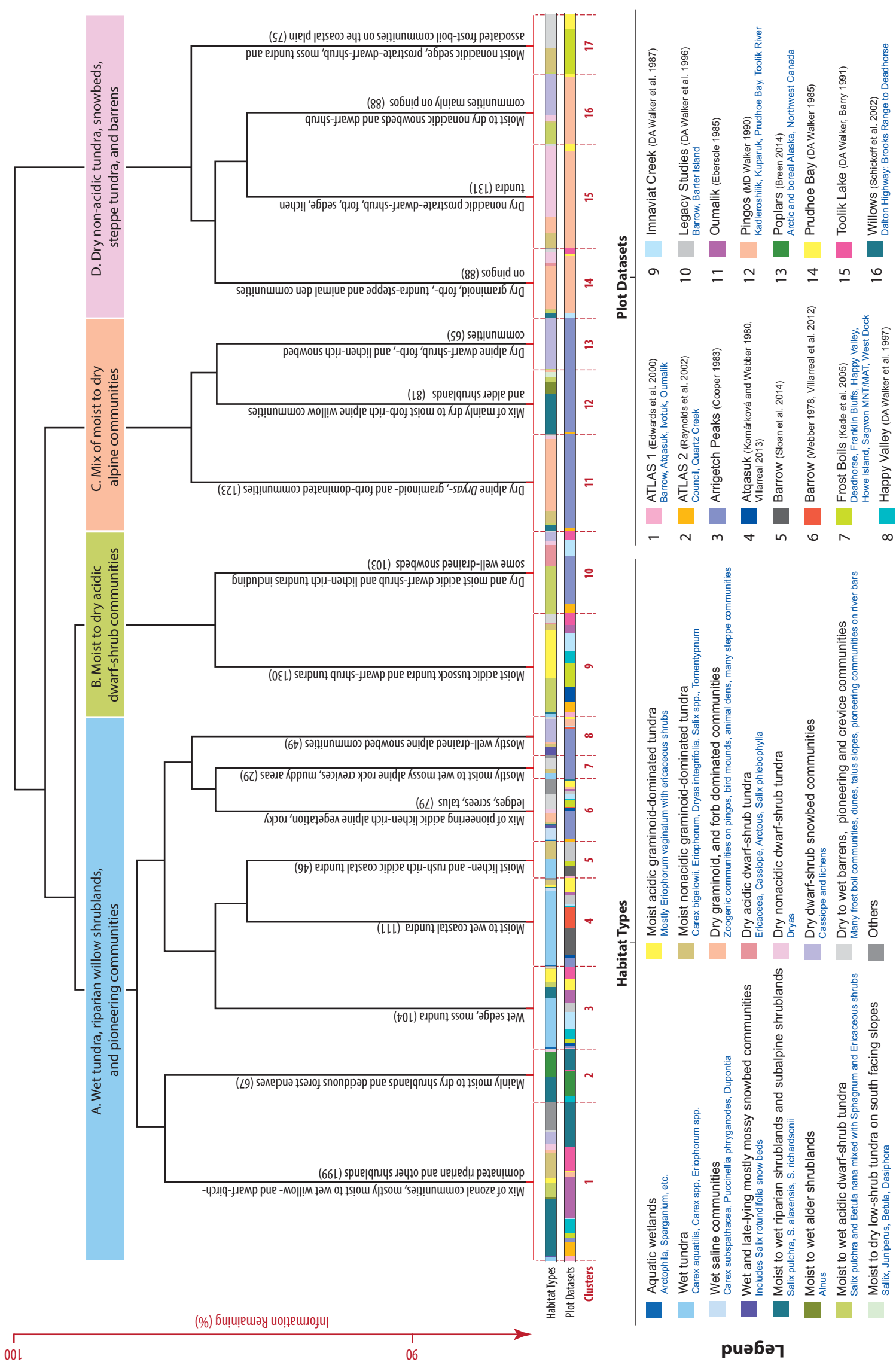

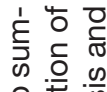

응 흔

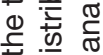

क

인

उ 30

象 $\frac{0}{5} \stackrel{\Phi}{5}$

눙

흥ㅇㅇ 으

응

\& 8

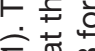

(1) क ल

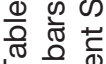

๘

은 응 웡

ㄷㅇㄱ 윽

묻

这

0 응

용 훙

워

क्षे

$\circ$

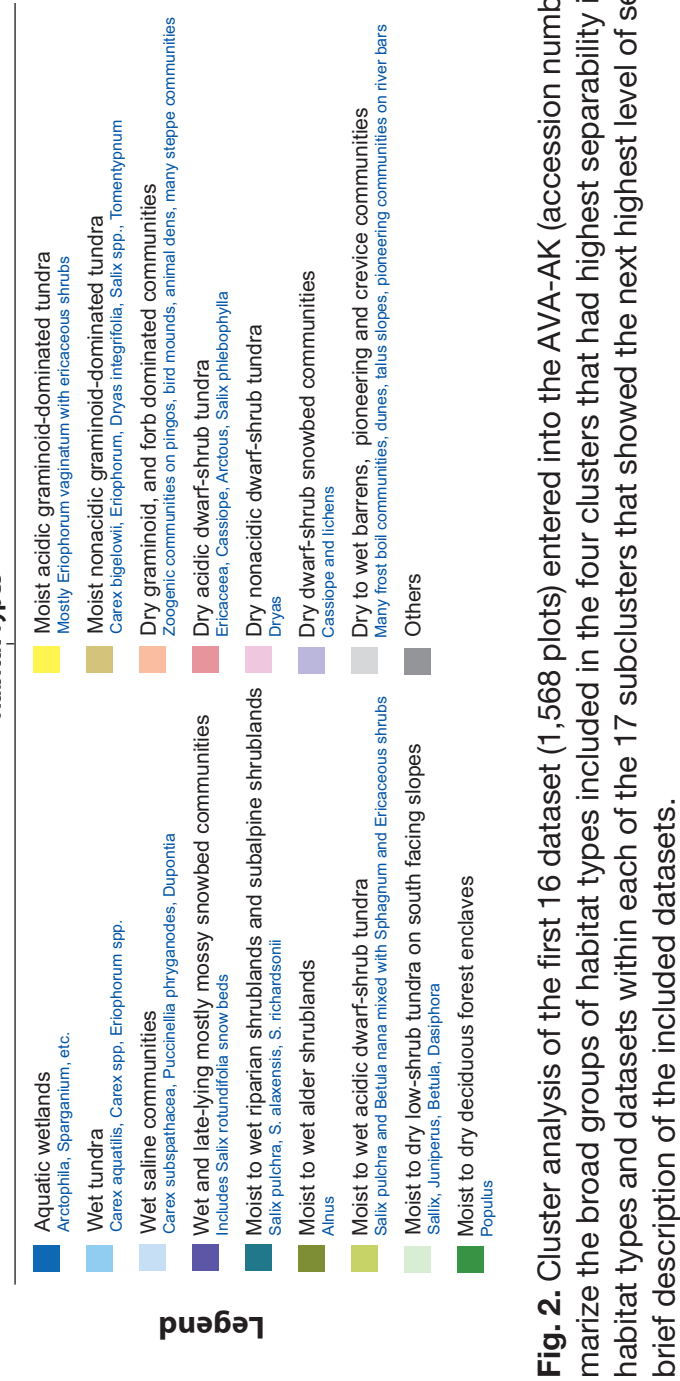


cal classes or alliances, as well as geographical or ecological affiliation of individual plant communities (Cluster A. - azonal as well as pioneer communities affected by specific environmental condition such as water gradient or disturbance regime; B. - Boreal heathland communities; C. - Alpine communities, D. - Graminoid tundra and $\mathrm{dwarf}$-shrub vegetation including various vegetation types from pingos. There are some artifacts/errors of spatial autocorrelation in our analysis where some plots from small regions representing different communities seem to be more similar than the same units from remote areas. The dominance of plots from the large Arrigetch Peaks (439 plots) and Pingos (293 plots) datasets in six of 17 subclusters of the preliminary cluster analysis indicates that these two datasets sampled much of the total habitat diversity at the drier end of the ecological gradients. These relatively large datasets also resulted in some spatial autocorrelation that resulted in the close clustering of most of these plots in a few large clusters at the highest level of the dendrogram.

\section{Evaluation}

The Alaska Arctic Vegetation Archive (AVA-AK) constitutes a major step toward consolidating existing plot data from Arctic Alaska into a single database with consistent species names that can be used for future classification and analysis of Arctic vegetation. A major strength of the AVA-AK is its web-portal, which makes the information easily accessible to users. The "Catalog" function of the portal links the species information in the Turboveg files to a wide variety of ancillary information for analyses. Several of the datasets are linked to field-based geoecological maps and remote-sensing land-cover maps in the Alaska Arctic Map Archive (AMA-AK).

\section{Data gaps}

Despite the importance of vegetation for studies of Arctic ecosystem change, the vegetation of large areas of Arctic Alaska remains unsurveyed. Only a few areas have been intensively sampled and mapped, mainly in the vicinity of permanent Arctic observatories, such as Barrow and the Toolik Research Station. Major data gaps occur in the sand region west of the Colville River, nearly all of the Arctic Foothills, the central and eastern Brooks Range, the west coast of Arctic Alaska, including Beringian, and species-rich habitats of the Seward Peninsula and the Yukon-Kuskokwim River delta. More data are needed from under-sampled habitat types, such as coastal salt marshes, sand dunes, aquatic communities, and the large variety of bedrock types and alpine habitats in the Brooks Range and Arctic Foothills.

\section{Need for a more consistent approach to tundra vegetation surveys}

The assembly and review of the AVA-AK revealed the need for a more consistent approach to survey Arctic vegetation so as to better support description and classification of Arctic vegetation. Although considerable amounts of vegetation data have been collected for various projects, much of the available information was project specific and was based on sampling protocols that are difficult to compare across sites. The older historical datasets were collected prior to the advent of the network of Global Positioning System (GPS) satellites and do not have accurate location information or permanently marked plots, thereby making it impossible to accurately resample these sites or link them to satellite-based observations. Some had questionable taxonomic determinations that were not supported by voucher collections, particularly for the cryptogam species, which limits the extrapolation potential of spatial distribution models that use these data. These and other inconsistencies across datasets point to the need for international standards for Arctic vegetation data collection (Walker et al. 2016). This problem is also recognized globally (De Cáceres et al. 2015).

\section{Urgency of archiving legacy data sets}

Assembly of the information for the archive pointed to the urgency to continue this work. Nearly every dataset required close communication with the author(s) to insure the accuracy of the information and that everything retrievable is archived, including field photos, maps, and information that may not have been in published reports. The retirement or death of the author(s) often meant loss of the original data and/or critical metadata information. For example, Vera Komárková collected a potentially major data set containing over 700 plots using BraunBlanquet protocols in the sand region of northern Alaska (Komárková \& McKendrick 1988), but the dataset could not be recovered because of her premature death in 2005 before the data could be processed and published.

\section{Conclusions}

Our preliminary analysis of first 16 datasets provides the first overview of the variability and hierarchical relationships of a broad spectrum of the plant communities in the Arctic region of Alaska. It has also identified gaps. We are continuing to add key datasets to the AVA-AK as they become available and anticipate many applications for examining biodiversity, vegetation classification, species distribution modeling, vegetation change modeling, landuse planning, resource development, and education. Our 
next step will be a full analysis of all the available datasets from Arctic Alaska. We expect this will be an iterative process as we link to Arctic vegetation archives from other parts of the Arctic.

The protocols developed for the AVA-AK could be applied elsewhere in the Arctic toward the goal of a panarctic vegetation database. Efforts are currently underway to apply the approach in Canada (MacKenzie 2014), Greenland (Bültmann \& Daniëls 2013) and to the Yamal Peninsula region of northwestern Russia (Ermokhina 2013). Application to the entire circumpolar region will require consensus approval of the approach with appropriate modification by the international community of Arctic vegetation scientists. The vision for an eventual panarctic AVA is that we will move to Turboveg v3 (Hennekens 2014), and model the AVA after the European Vegetation Archive (EVA) (Chytrý et al. 2016). This would allow several independent national databases to be stored in the archive.

\section{Author contributions}

M.D.W. \& D.A.W. conceived the database. D.A.W., A.L.B., L.A.D.\& J.S. created the database and wrote the manuscript. J.P. prepared the figures and edited the report. S.H. provided advice and help with the Turboveg database. J.S. conducted the cluster analysis. H.E.E. and M.B. provided remote-sensing and biomass ancillary datasets and organized these data. M.K.R., A.L.B, S.H. and several other coauthros developed the Pan Arctic Species List. L.W.W., W.F., M.B. \& J.P. were principally responsible for the web portal and system support; R.K.P. \& M.T.L. provided guidance for transferal of data to VegBank and overall database guidance. F.J.A.D. \& H.B. provided help with Braun-Blanquet classification and conceptual framework for the study. D.A.W., A.L.B., M.K.R., M.B., M.D.W., K.B., T.B., D.J.C., S.J.D., J.J.E., H.E.E., S.C.E. W.A.G., R.D.H., C.M.I., M.T.J., A.K., W.H.M., U.S., V.L.S., S.S.T., S.V., P.J.W., and D.Z. provided datasets.

\section{Acknowledgments}

Funding for the AVA-AK came from the NASA ArcticBoreal Vulnerability Experiment (ABoVE) initiative (Grant No. NNX13AM20G). The project was conceived and endorsed by the Flora Working Group of the Conservation of Arctic Flora and Fauna (CAFF), the biodiversity working group of the Arctic Council. Other funding came from the NASA Land Cover and Land-Use Change program (Award No. NNX14AD0G) and the NSF Arctic Science Engineering and Education for Sustainability (ArcSEES) inititiative (Award No. 1233854).

\section{References}

Botta-Dukát, Z., Chytrý, M. \& Hájková, P. 2005. Vegetation of lowland wet meadows along a climatic contenentality gradient in Central Europe. Preslia 77: 89-111.

Breen, A.L., Druckenmiller, L., Hennekens, S.M., Raynolds, M.K., Walker, M.D. \& Walker, D.A. 2014. Progress toward an Alaska prototype for the Arctic Vegetation Archive: Workflow and data dictionary. CAFF Proceeding Series Report 11: 7-21.

Bültmann, H. \& Daniëls, F.J.A. 2013. Greenland data stored in the Arctic Vegetation Archive (AVA) in Münster. CAFF Proceedings Series Report 10: 29-32.

Chytrý, M., Hennekens, S.M., Jíménez-Alfaro, B., Knollová, I., Dengler, J., Jansen, F., Landucci, F., Schaminée, J.H.J., Aćić, S., (...) \& Yamalov, S. 2016. European Vegetation Archive (EVA): an integrated database of European vegetation plots. Applied Vegetation Science 19: 173-180.

Cooper, D.J. (1986) Arctic-alpine tundra vegetation of the Arrigetch Creek Valley, Brooks Range, Alaska. Phytocoenologia, 14: 467-555.

De Cáceres, M., Chytrý, M., Agrillo, E., Attorre, F., BottaDukát, Z., Capelo, J., Czúcz, B., Dengler, J., Ewald, J., (...) \& Wiser, S. K. 2015. A comparative framework for broadscale plot-based vegetation classification. Applied Vegetation Science, 18: 543-560.

Dengler, J. \& the sPlot Core Team. 2014. sPlot: the first global vegetation-plot database and opportunities to contribute. IAVS Bulletin 2014(2): 34-36.

Dengler, J., Jansen, F., Glöckler, F., Peet, R.K., De Cáceres, M., Chytrý, M., Ewald, J., Oldeland, J., Lopez-Gonzalez, G., (...) \& Spencer, N. 2011. The Global Index of VegetationPlot Databases (GIVD): a new resource for vegetation science. Journal of Vegetation Science 22: 582-597.

Elven, R. 2011. Annotated checklist of the panarctic flora (PAF): vascular plants. National Centre of Biosystematics, Natural History Museum, University of Oslo, Oslo, NO.

Ermokhina, K. 2013. Yamal and Gydan vegetation datasets. Arctic Vegetation Archive CAFF Proceedings Series Report 10: 40-44.

Hennekens, S.M. \& Schaminée, J.H.J. 2001. TURBOVEG, a comprehensive data base management system for vegetation data. Journal of Vegetation Science 12: 589-591.

Hennekens, S. 2014. Turboveg v3: a gateway to vegetation plot data. URL: http://www.botanik.uni-greifswald.de/ fileadmin/workshop/2014/TV3_Koblenz_Feb_2014.pdf [accessed 14 May 2016].

Komárková, V. \& McKendrick, J.D. 1988. Patterns in vascular plant growth forms in arctic communities and environment at Atkasook, Alaska. In: Werger, M.J.A., van der Aart, P.J.M. During, H.J. \& Verhoeven, J.T.A. (eds.) Plant form and vegetation structure, pp. 45-70. SPB Academic Publishing, The Hague, NL.

Konstantinova, N.A. \& Bakalin, V.A. 2009. Checklist of liverworts (Marchantiophyta) of Russia. Arctoa 18: 1-64.

Kristinsson, H., Steen Hansen, E. \& Zhurbenko, M.P. 2010. Panarctic lichen checklist. CAFF Technical Report 20: 1-120.

MacKenzie, W.H. 2014. The Canadian Arctic Vegetation Archive (CAVA) and a preliminary classification of Canadian arctic vegetation. CAFF Proceedings Series Report 11: 56-59.

Peet, R.K., Lee, M.T., Jennings, M.D. \& Faber-Langendoen, D. 2012. VegBank - a permanent, open-access archive for vegetation-plot data. Biodiversity and Ecology 4: 233-241.

Raynolds, M.K., Breen, A.L., Walker, D.A., Elven, R., Murray, D.F., Belland, R., Konstantinova, N.A., Kristinsson, H. \& 
Hennekens, S.M. 2013. The Pan-Arctic Species List (PASL). CAFF Proceedings Series Report 10: 92-95.

Tichý, L., Holt, J. \& Nejezchlebová, M. 2011. JUICE program for management, analysis and classification of ecological data ( $2^{\text {nd }}$ edition). Vegetation Science Group, Masaryk University, Brno, CZ. URL: http://www.sci.muni.cz/botany/juice/ JCman2011_1st.pdf.

Walker, D.A. 2014a. Toward a pan Arctic vegetation archive and classification: Two recent workshops. IAVS Bulletin 2014(1): 12-16.

Walker, D.A. (ed.) 2014b. Alaska Arctic Vegetation Archive (AVA) Workshop, Boulder, Colorado, USA, October 14-16, 2013. Conservation of Arctic Flora and Fauna (CAFF) [CAFF Proceedings Report no. 11], Akureyri, IS.

Walker, D.A. \& Raynolds, M.K. 2011. An International Arctic Vegetation Database: a foundation for panarctic biodiversity studies. CAFF Strategy Series Report 5: 1-28.

Walker, D.A., Breen, A.L., Raynolds, M.K. \& Walker, M.D. (eds.) 2013a. Arctic Vegetation Archive Workshop, Krakow, Poland, April 14-16, 2013 . Conservation of Arctic Flora and
Fauna (CAFF) [CAFF Proceedings Report no. 10], Akureyri, IS.

Walker, D.A., Alsos, I.G., Bay, C., Boulanger-Lapointe, N., Breen, A.L., Bültmann, H., Christiansen, T., Damgaard, C., Daniëls, F.J.A., (...) \& Wisz, M.S. 2013b. Rescuing valuable Arctic vegetation data for biodiversity models, ecosystem models and a panarctic vegetation classification. Arctic 66: 133-137.

Walker, D.A., Daniëls, F.J.A., Alsos, I., Bhatt, U.S., Breen, A.L., Buchhorn, M., Bültmann, H., Druckenmiller, L.A., Edwards, M.E., (...) \& Webber, P.J. 2016. Circumpolar Arctic vegetation: A hierarchic review and roadmap toward an internationally consistent approach to survey, archive and classify tundra plot data. Environmental Research Letters 11: Article 055005.

Walker, M.D. 1990. Vegetation and floristics of pingos, Central Arctic Coastal Plain, Alaska. Dissertationes Botanicae 149: $1-283$.

\section{Author addresses}

Donald A. Walker (Corresponding author: dawalker@alaska.edu) ${ }^{1}$, Amy L. Breen (albreen@alaska.edu) ${ }^{1,2}$, Lisa A. Druckenmiller (ladruckenmiller@alaska.edu) ${ }^{1}$, Lisa W. Wirth (lisa@gina.alaska.edu) ${ }^{3}$,Will Fisher (will@alaska.edu) ${ }^{3}$, Martha K. Raynolds (mkraynolds@alaska.edu) ${ }^{1}$, Jozef Šibík (jozef.sibik@savba.sk) ${ }^{4}$, Marilyn D. Walker (marilyn@homerenergy.com) ${ }^{5}$, Stephan Hennekens (stephan.hennekens@wur.nl) ${ }^{6}$, Keith Boggs (kwboggs@uaa.alaska.edu) ${ }^{7}$, Tina Boucher (tboucher@uaa.alaska.edu) ${ }^{7}$, Marcel Buchhorn (mbuchhorn@alaska.edu) ${ }^{1,8}$, Helga Bültmann (bultman@uni-muenster.de) ${ }^{9}$, David J. Cooper (David. Cooper@colostate.edu) ${ }^{10}$, Fred J.A Daniëls (daniels@uni-muenster.de) ${ }^{9}$, Scott J. Davidson (sjdavidson1@sheffield.ac.uk) ${ }^{11}$, James J. Ebersole (jebersole@ColoradoCollege.edu)12, Sara C. Elmendorf (selmendorf@neoninc.org) ${ }^{13}$, Howard E. Epstein (hee2b@virginia.edu) $)^{14}$, William A. Gould (wgould@fs.fed.us) ${ }^{15}$, Robert D. Hollister (hollistr@gvsu.edu) ${ }^{16}$, Colleen M. Iversen ${ }^{17}$, M.Torre Jorgenson (ecoscience@alaska.net) ${ }^{18}$, Anja Kade (ankade@alaska.edu) ${ }^{1}$, Michael T. Lee (michael.lee@unc.edu) ${ }^{19}$, William H. MacKenzie (will.mackenzie@gov.bc.ca) ${ }^{20}$, Robert K. Peet (peet@unc.edu) ${ }^{19}$, Jana L. Peirce (jlpeirce@alaska.edu) ${ }^{1}$, Udo Schickhoff (Udo.Schickhoff@t-online.de) $)^{21}$, Victoria L. Sloan (v.l.sloan@bristol.ac.uk) ${ }^{22}$, Stephen S. Talbot (stephen_ talbot@fws.gov)23, Craig E. Tweedie (ctweedie@utep.edu) ${ }^{23}$, Sandra Villarreal (svillarreal51@gmail.com) ${ }^{23}$, Patrick J. Webber (webber@msu.edu) $)^{24}$, Donatella Zona (D.zona@sheffield.ac.uk) $)^{11,25}$

${ }^{1}$ Alaska Geobotany Center, Institute of Arctic Biology, University of Alaska Fairbanks, Fairbanks, AK, 99775, United States

${ }^{2}$ International Arctic Research Center, University of Alaska, Fairbanks, AK, 99775, United States

${ }^{3}$ Geographic Information Network of Alaska, Geophysical Institute, University of Alaska Fairbanks, Fairbanks, AK, 99775, United States

${ }^{4}$ Institute of Botany, Department of Geobotany, Slovak Academy of Sciences, Dúbravská cesta 9, 845 23, Bratislava, Slovak Republic

${ }^{5}$ HOMER Energy, $179030^{\text {th }}$ St. Boulder, CO, 80301, United States

${ }^{6}$ Alterra, Wageningen, Box 47, $6700 \mathrm{~PB}$, The Netherlands

${ }^{7}$ Alaska Natural Heritage Program, Alaska Center for Conservation Science, University of Alaska Anchorage, 3211 Providence Drive, Anchorage, Alaska 99508, United States

${ }^{8}$ HyLab, Geophysical Institute, University of Alaska Fairbanks, Fairbanks, AK, 99775, United States

${ }^{9}$ Institute for Plant Ecology, University of Münster, Schlossplatz 8, 48143 Münster, Germany

${ }^{10}$ Department of Forest and Rangeland Stewardship, Colorado State University, Fort Collins, CO, United States

${ }^{11}$ Department of Animal and Plant Sciences, University of Sheffield, Western Bank, south Yorkshire, S10 2TN, United Kingdom

${ }_{12}$ Biology Department, Colorado College, Colorado Springs, CO, 80903, United States;

${ }^{13} \mathrm{NEON}$, Inc., $168538^{\text {th }}$ St, Boulder, CO, 80301, United States

${ }^{14}$ Department of Environmental Sciences, University of Virginia, Charlottesville, VA, 22904, United States

${ }^{15}$ US Forest Service, International Institute of Tropical Forestry, Jardin Botanico Sur, Rio Piedras, Puerto Rico, 00926, United States

16 Department of Biology, Grand Valley State University, Alendale, MI, 49401, United States

${ }^{17}$ Environmental Science Division, Oak Ridge National Laboratory, Oak Ridge TN, 37831, United States

${ }_{18}$ Alaska Ecoscience, 2332 Cordes Way, Fairbanks, AK, 99709, United States

${ }^{19}$ Department of Biology, University of North Carolina, Chapel Hill, NC, 27599-3280, United States

${ }^{20}$ B.C. Ministry of Forests, Lands and Natural Resources, Bag 6000, Smithers, B.C. VOJ 2NO, Canada

${ }^{21}$ Institute of Geography, University of Hamburg, Bundesstraße 55, 20146 Hamburg, Germany 
${ }^{22}$ Faculty of Engineering, Queens Building, University Walker, Clifton, BS8 1TR, United Kingdom

${ }^{23}$ US Fish and Wildlife Service, 1011 E. Tudor Road, Anchorage, AK, 99503, United States

${ }^{24}$ Systems Ecology Lab, Department of Biological Sciences, University of Texas El Paso, TX, 79902, United States

${ }^{25}$ Department of Plant Biology (Emeritus), Michigan State University, Ann Arbor, MI, 48824, United States

${ }^{25}$ Department of Biology, San Diego State University, San Diego, CA, 92182, United States

\section{Electronic Supplements}

Supplementary material associated with this article is embedded in the pdf of this article. The online version of Phytocoenologia is hosted at www.ingentaconnect.com/content/schweiz/phyt and the journal's website http://www.schweizerbart.com/journals/ phyto. The publisher does not bear any liability for the lack of usability or correctness of supplementary material.

Supplement S1: Data dictionary for the AVA-AK.

Supplement S2: Overview of vegetation surveys in Arctic Alaska and contents of the AVA-AK.

Supplement S3: Cluster analysis of the first 16 datasets in the Alaska Arctic Vegetation Archive (AVA-AK).

Please download the electronic supplement and rename the file extension to .zip (For security reasons Adobe does not allow to embed .exe, .zip, .rar etc. files). 